\title{
Pathological and Ultra-structural Changes in Testis of Rats due to Doxorubicin Toxicity and its Amelioration with Quercetin
}

\author{
S. Divya ${ }^{1}$, D. Madhuri ${ }^{*}$, M. Lakshman ${ }^{1}$ and A. Gopal Reddy ${ }^{2}$ \\ ${ }^{1}$ Department of Veterinary Pathology, College of Veterinary Science, Rajendranagar, \\ Hyderabad-500030, Telangana, India \\ ${ }^{2}$ Department of Veterinary Pharmacology and Toxicology, College of Veterinary Science, \\ Rajendranagar, Hyderabad-500030, Telangana, India \\ *Corresponding author
}

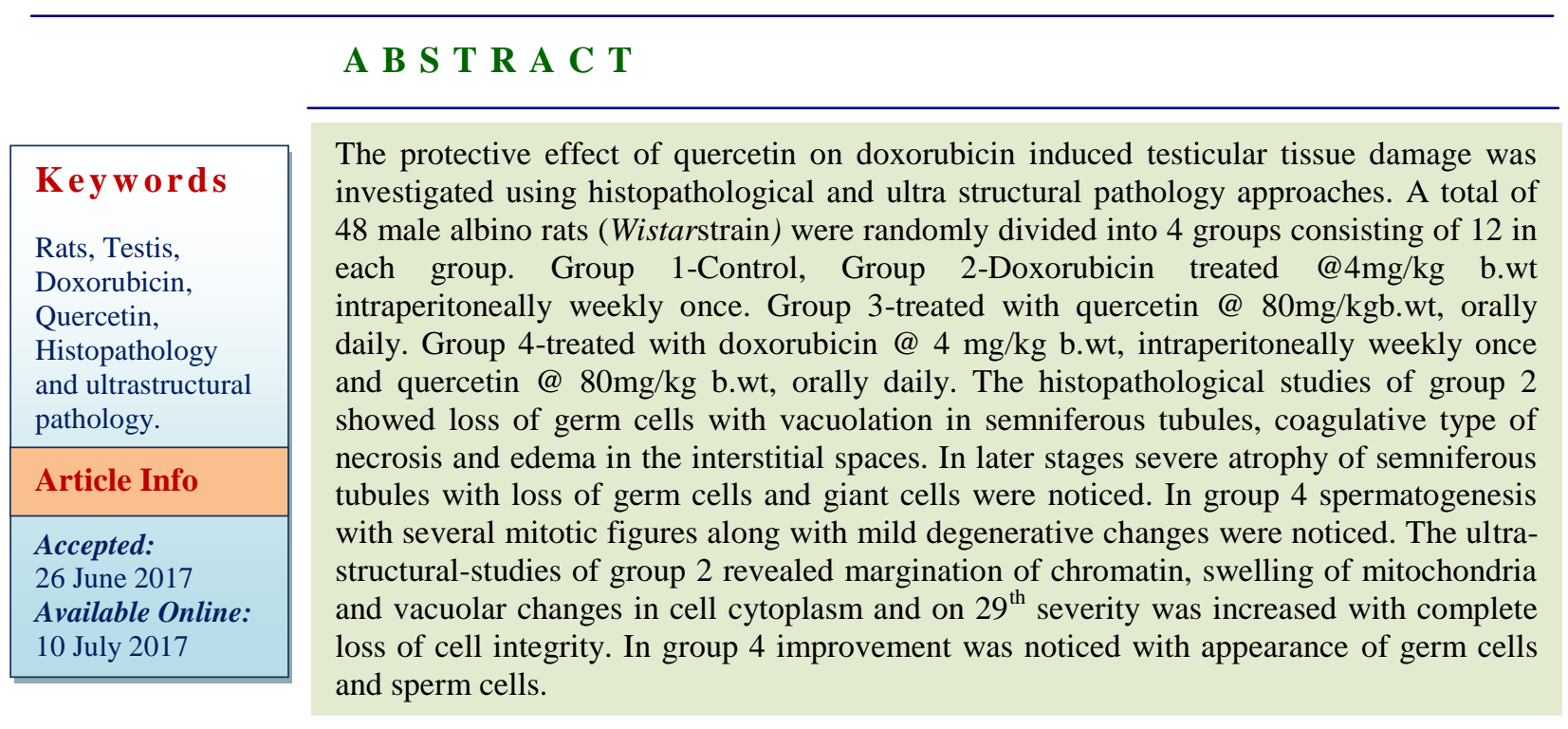

\section{Introduction}

Anthracyclins are currently the most effective group of antineoplastic drugs used in clinical practice, among them Doxorubicin (DOX), is a key chemotherapeutic agent in cancer treatment, isolated from the soil fungus Streptomyces peucetiuscaesius. Doxorubicin, known as topoisomerase II (TOP2) poison, blocks the synthesis of DNA by intercalating into the DNA strand. Although doxorubicin is considered a very potent and efficient chemotherapeutic drug, it also kills healthy cells, especially those under rapid and constant proliferation. Therefore, DNA of rapidly dividing cells such as the testicular germ cells can be the preferential target of doxorubicin resulting in reproductive toxicity. DOX-induced organopathy involves the generation of free radicals which result in membrane and macromolecule damage by lipid peroxidation, DNA fragmentation and protein oxidation (Granados-Principal et al., 2010). Because of high concentration of polyunsaturated fatty acids and low antioxidant capacity the mammalian 
spermatozoa are more vulnerable to oxidative damage (Vernet et al., 2004). Dox causes an imbalance between free oxygen radicals (ROS) and antioxidants enzymes resulting in tissue injury.

Quercetin (3, 3', 4', 5, 7- pentahydroxyflavones) is a plant pigment an important dietary flavonoid found in a variety of plantbased foods such as Red-onions, broccoli, apples, cherries, berries and tea. It is considered to be a strong antioxidant due to its ability to scavenge free radicals and bind transition metal ions (Hollman and Katan 1997; Sakanashi et al., 2008).

Hence the objective of this study was to assess the reproductive toxicity in male albino Wistar rats induced by doxorubicin and ameliorative effect of quercetin to overcome the doxorubicin induced testicular toxicity

\section{Materials and Methods}

A total of 48 male albino rats (Wistarstrain) weighing $250-280 \mathrm{~g}$ were procured from Sanzyme laboratories Ltd., Hyderabad and were randomly divided into 4 groups consisting of 12 in each group. Group 1Control, Group 2-Doxorubicin treated @ $4 \mathrm{mg} / \mathrm{kg}$ b.wt intraperitoneally weekly once. Group 3-treated with quercetin @ 80mg/kg b.wt, orally daily. Group 4-treated with doxorubicin @ $4 \mathrm{mg} / \mathrm{kg} \quad$ b.wt, intraperitoneally weekly once and quercetin @ 80mg/kg b.wt, orally daily. The experiment was carried out according to the guidelines and prior approval of the Institutional Animal Ethics Committee (IAEC).

The animals were sacrificed at fortnight intervals. From each group, 6 rats were sacrificed on $15^{\text {th }}$ day and remaining were sacrificed on $29^{\text {th }}$ day. The abdominal cavity was opened through a midline abdominal incision to expose the reproductive organs. Then the testes were excised and trimmed of all fat. The gross pathology and testes weights of each animal were evaluated. The testes from all the groups were collected for histopathological and ultra-structural studies in suitable preservatives. For histopathological examination the testes samples were collected and fixed in $10 \%$ neutral buffer formalin (NBF) soon after sacrifice. The samples were processed, sectioned $(5 \mu \mathrm{m})$ and stained with Hematoxylin and Eosin (H\&E) as per the standard procedure (Luna, 1968). To study the ultra-structural Pathology the testes samples were collected and preserved in $2.5 \%$ gluteraldehyde (PBS based EM grade) and processed for transmission electron microscopic (TEM) study asper the standard protocol (Bozzala and Russels, 1998).

\section{Results and Discussion}

\section{Absolute testicular weights (g)}

Testes weight in different groups on day 15 and 29 is shown in the table 1 . Testes weights (g) were taken immediately after sacrifice and the weight was significantly $(\mathrm{P}<0.05)$ reduced in doxorubicin treated group (2.09) when compared with Group 1 (2.88), Group 3 (2.64) and Group 4 (2.43) on 15th day. Similarly on 29th day also a significant reduction in testicular weights was noticed in Group 2 (1.07) compared with control (2.71), Group 3 (2.60) and Group 4 (1.38). The testicular weights of Group 1 and Group 3 were comparable with each other.

\section{Relative testicular weights (g)}

The mean values of relative testicular weight was significantly $(\mathrm{P}<0.05)$ reduced in Group 2 $(0.95,0.36)$ compared with Group 1 (1.11, 1.09), Group $3(1.08,1.00)$ and Group 4 $(1.10,0.64)$ on 15 th and 29th day 
respectively. There was no significant difference between Group 1 and Group 3 on 15 th and 29th day of experiment.

\section{Gross pathology}

On 15th and 29th day of experiment the testicular size of Group 2 decreased compared with Group 1, Group 3 and Group 4.

\section{Histopathology}

The examination of testicular sections of control group on day 15 and day 29 of the experiment showed normal seminiferous tubules with active spermatogenesis. Each tubule is bounded by a basal lamina, spermatogenic cells and sertoli cells. Spermatogenic cells were arranged in layers occupying space between basement membrane and lumen of tubule (Fig. 1). In between the tubules i.e. in interstitial space fibroblasts, collagen, blood vessel and Leydig cells are present. The histopathological sections of Group 3 testes showed normal seminiferous tubules with regular outlines as noticed in control. They were lined in 4-6 layers of germinal epithelium at different stages of spermatogenesis (Fig. 2) and the lining epithelium consisted of sertoli cells. On day 15 the testicular sections of Group 2 revealed disorganized, disrupted epithelium of affected tubules and shedding of germ cells in to the lumen. In most of the seminiferous tubules vacuolation was observed (Fig. 3). In some seminiferous tubules complete loss of cells and necrosis of germ cells was characterized by presence of large pale eosinophilic mass and few retained spermatids were noticed at the base of seminiferous tubules. In addition to changes in seminiferous tubules, the interstitial tissue was widened, edema and vacuoles were noticed. On day 29 the testicular sections of Group 2 showed disrupted spermatogenic cells in many seminiferous tubules. Most of the seminiferous tubules were devoid of germ cells with dilated lumen (Fig. 4). In few seminiferous tubules syncytia/giant cell formation was noticed. Almost all the seminiferous tubules showed severe atrophy as they were devoid of epithelium (Fig. 5).

In Group 4 the testicular sections on day 15 revealed nearly normal seminiferous tubules except for widening of interstitial space (Fig. 6). In Group 4 most of the seminiferous tubules exhibited spermatogenesis (Fig. 7) and several mitotic figures could be seen in spermatogenic cells. Most of the seminiferous tubule showed organized epithelium except in few tubules mild degenerative changes and disorganized arrangement of germ cells were noticed.

\section{Ultra Structure}

The ultrastructure examination of rat testis from control group and Group 3 showed normal seminiferous tubular structures surrounded by a thick basal lamina and myoid cells. The spermatogonia resting on basal lamina with large nucleus and centrally placed prominent electron dense nucleolus, the spermatocytes with spherical nucleus containing electron dense hetero and euchromatin masses distributed in the nucleoplasma and cytoplasm showed numerous light and dense mitochondria (Fig. 8). The ultrathin sections revealed the presence of numerous sperms at different stages with different sizes and shapes. The Group 2 sections on 15th day revealed variable degrees of degenerative changes in germ cells including thin basement membrane, numerous distorted spermatogenic cells, cytoplasmic vacuolation with swollen mitochondria. Few primary spermatocytes showed mild margination of chromatin material and presence of abnormal sperms were appears to be typical (Fig. 9). 
Table.1 Absolute and relative testis weight $(\mathrm{g})$ in different groups on day 15 and 29 of the experimental period

\begin{tabular}{|l|l|l|l|}
\hline Group & Day & $\begin{array}{l}\text { Absolute } \\
\text { testis weight }\end{array}$ & $\begin{array}{l}\text { Relative testis } \\
\text { weight }\end{array}$ \\
\hline I & 15 & $2.88 \pm 0.08^{\mathrm{a}}$ & $1.11 \pm 0.03^{\mathrm{a}}$ \\
\hline II & 15 & $2.09 \pm 0.12^{\mathrm{c}}$ & $0.95 \pm 0.05^{\mathrm{b}}$ \\
\hline III & 15 & $2.64 \pm 0.10^{\mathrm{ab}}$ & $1.08 \pm 0.03^{\mathrm{a}}$ \\
\hline IV & 15 & $2.43 \pm 0.12^{\mathrm{b}}$ & $1.10 \pm 0.05^{\mathrm{a}}$ \\
\hline I & 29 & $2.71 \pm 0.03^{\mathrm{a}}$ & $1.09 \pm 0.02^{\mathrm{a}}$ \\
\hline II & 29 & $1.07 \pm 0.13^{\mathrm{c}}$ & $0.36 \pm 0.04^{\mathrm{c}}$ \\
\hline III & 29 & $2.60 \pm 0.04^{\mathrm{a}}$ & $1.00 \pm 0.02^{\mathrm{a}}$ \\
\hline IV & 29 & $1.38 \pm 0.13^{\mathrm{b}}$ & $0.64 \pm 0.05^{\mathrm{b}}$ \\
\hline
\end{tabular}

Values are Mean + SE $(n=6)$ One way ANOVA Means with different superscripts differ significantly $(\mathrm{P}<0.05)$

Fig.1 Group 1 showing the spermatogenic cells arranged in layers occupying space between Basement membrane and lumen of tubule. H\&E 400

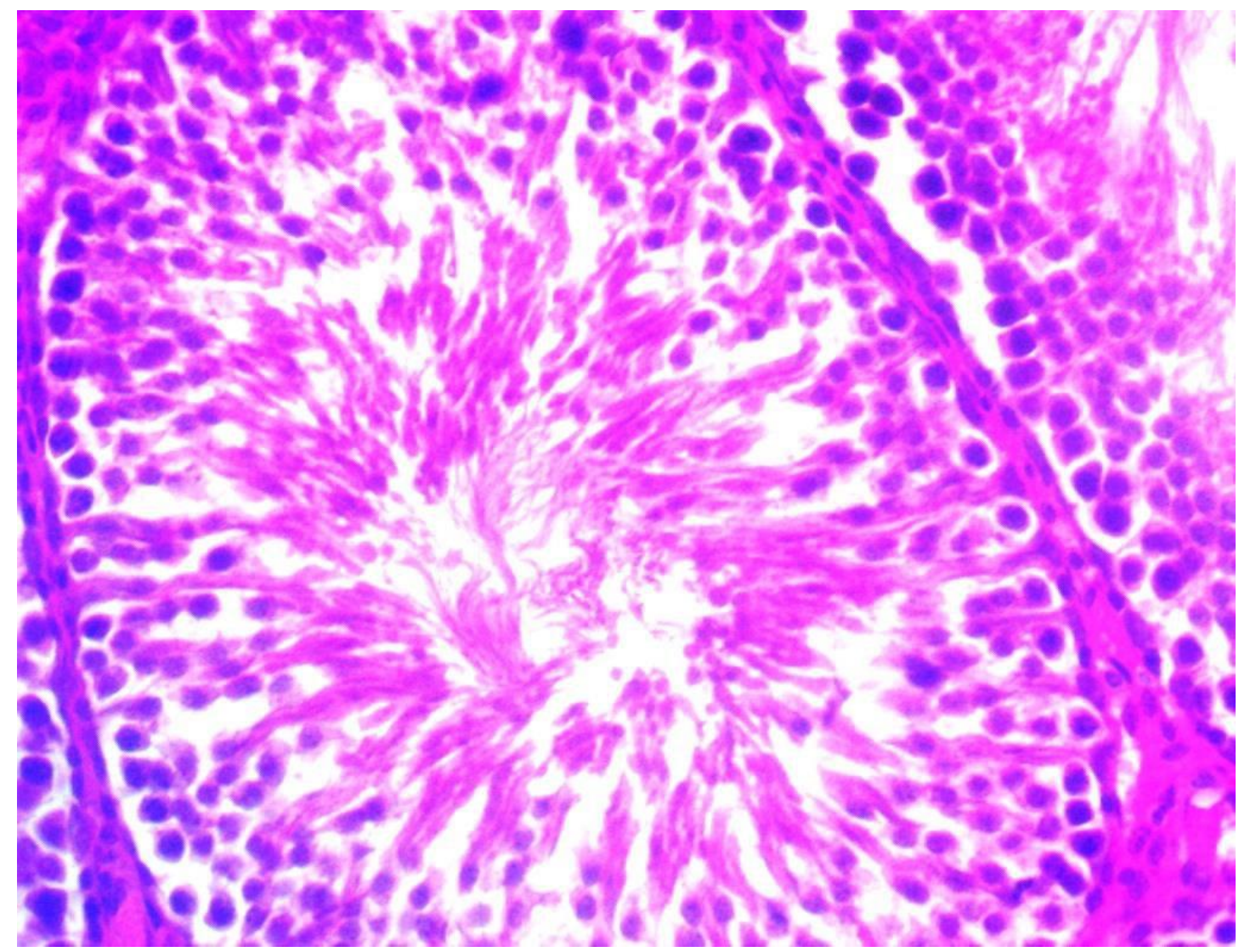


Fig.2 Microphotograph of Group 3 showing normal seminiferous epithelium and interstitial Tissue with active spermatogenesis and spermatozoa filled in lumen. H\&E×400

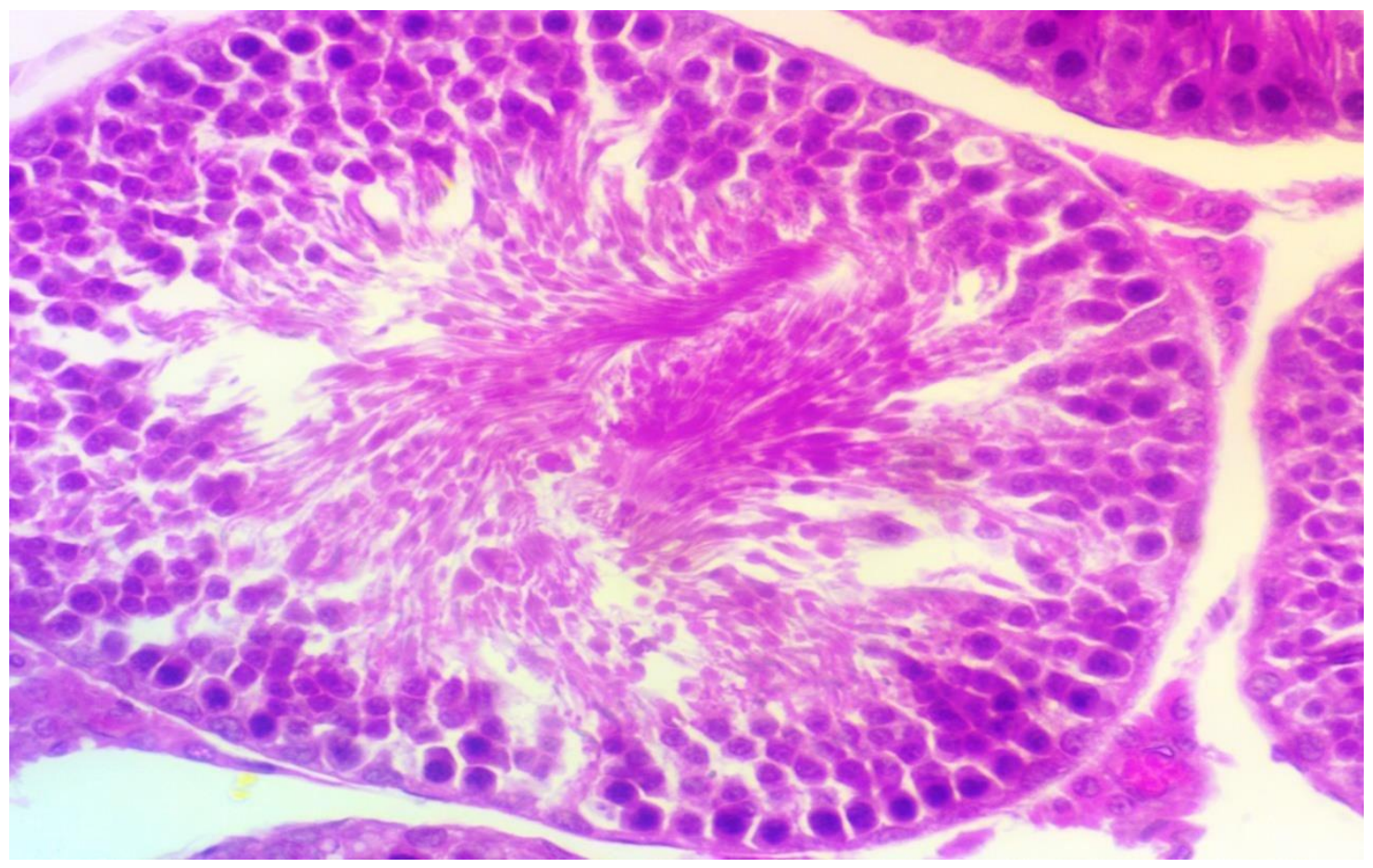

Fig.3 Microphotograph of Group 2 showing tubular vacuolation with loss of germ cells on $15^{\text {th }}$ day. $\mathrm{H} \& \mathrm{E} \times 400$

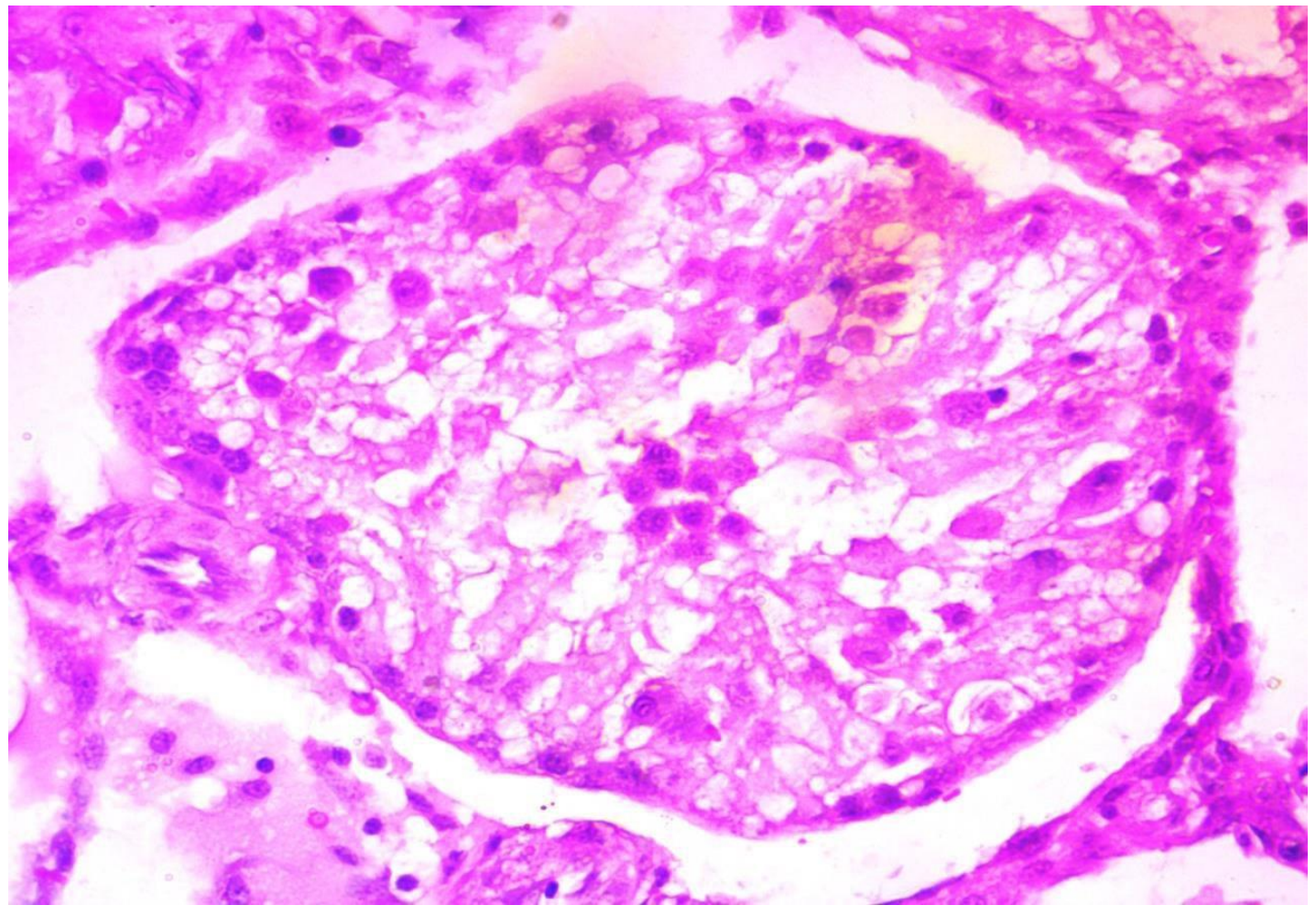


Fig.4 Microphotograph of Group 2 showing widening of interstitial space, loss of germinal Epithelium with dilated lumen of seminiferous tubule on $29^{\text {th }}$ day. $H \& E \times 400$

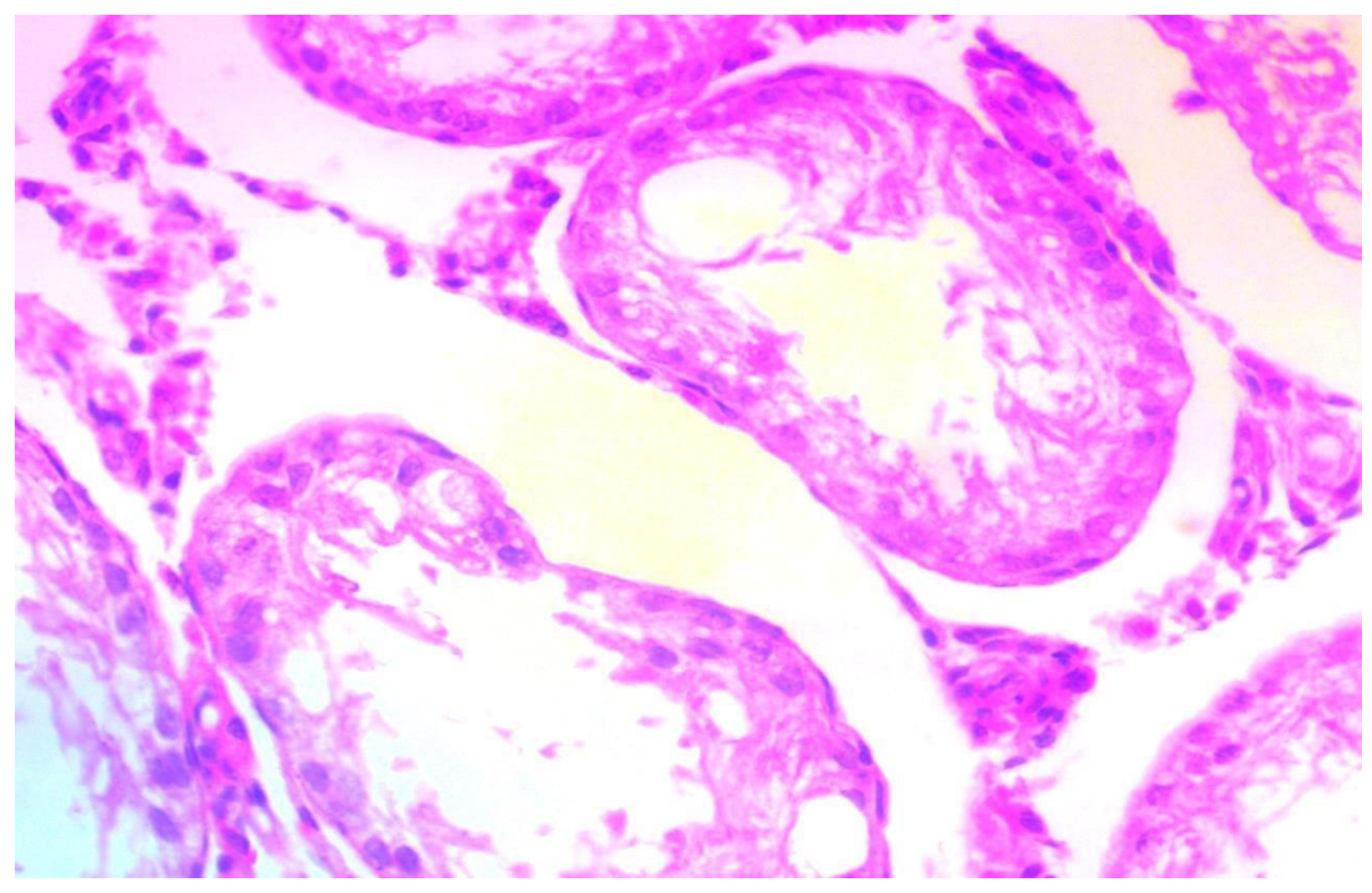

Fig.5 Microphotograph of Group 2 showing seminiferous tubules with severe atrophy and Devoid of germinal epithelium on $29^{\text {th }}$ day. $H \& E \times 100$

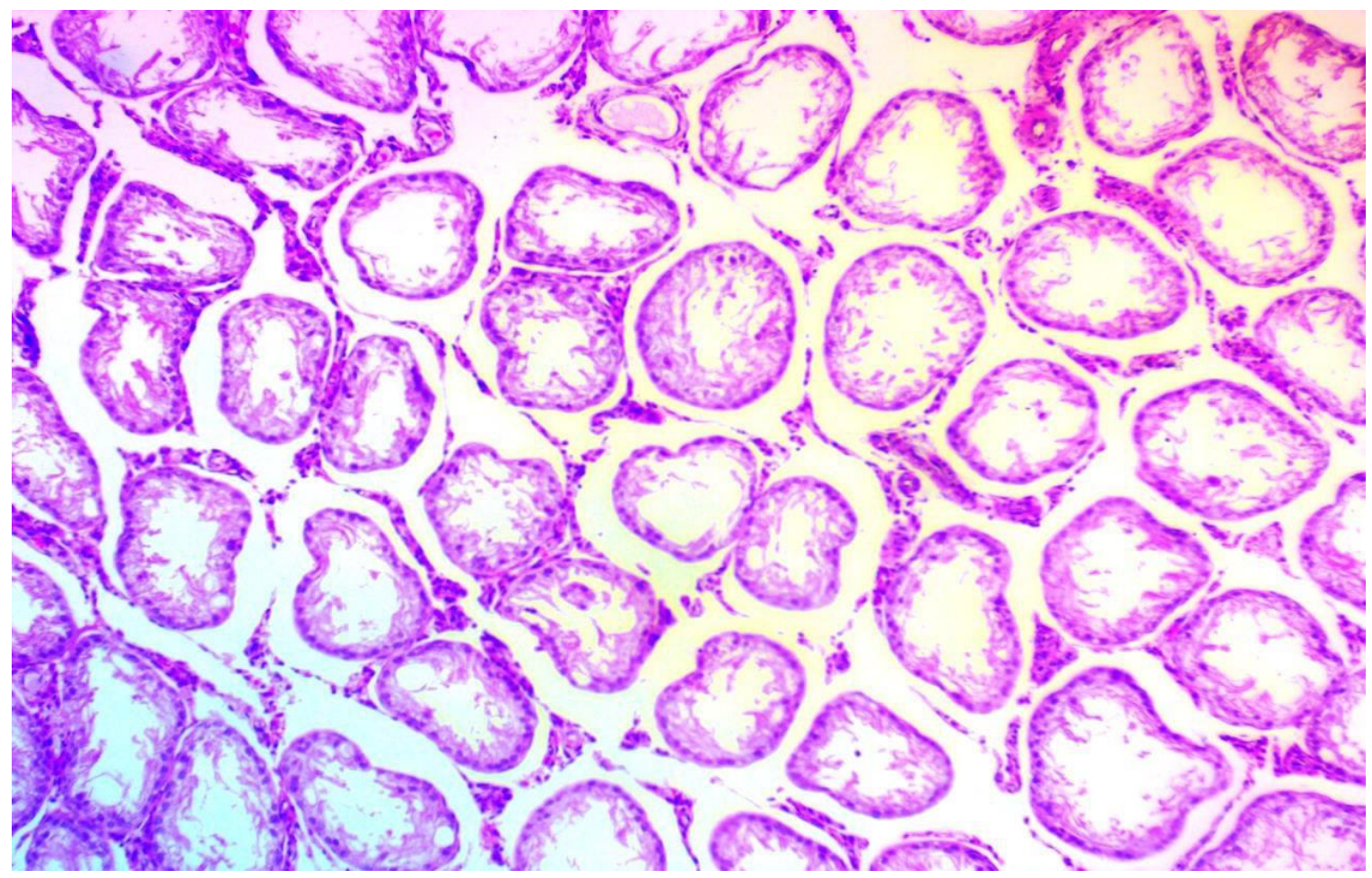


Fig.6 Microphotograph of Group 4- showing widening of interstitial space and seminiferous Tubules were nearly normal with spermatogenesis on $15^{\text {th }}$ day. $H \& E \times 100$

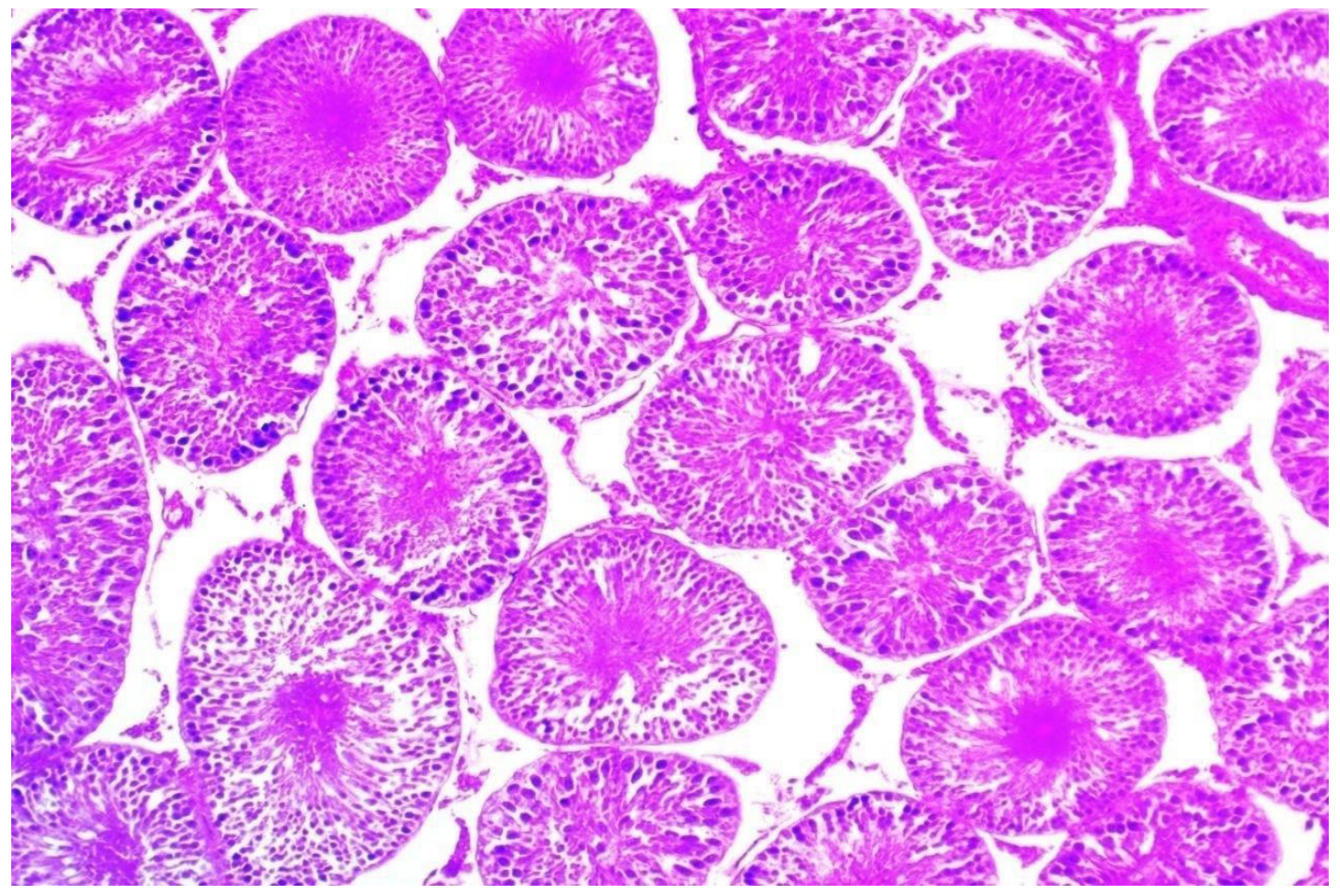

Fig.7 Microphotograph of Group 4 showing seminiferous tubules exhibiting spermatogenesis on $29^{\text {th }}$ day. $H \& E \times 100$

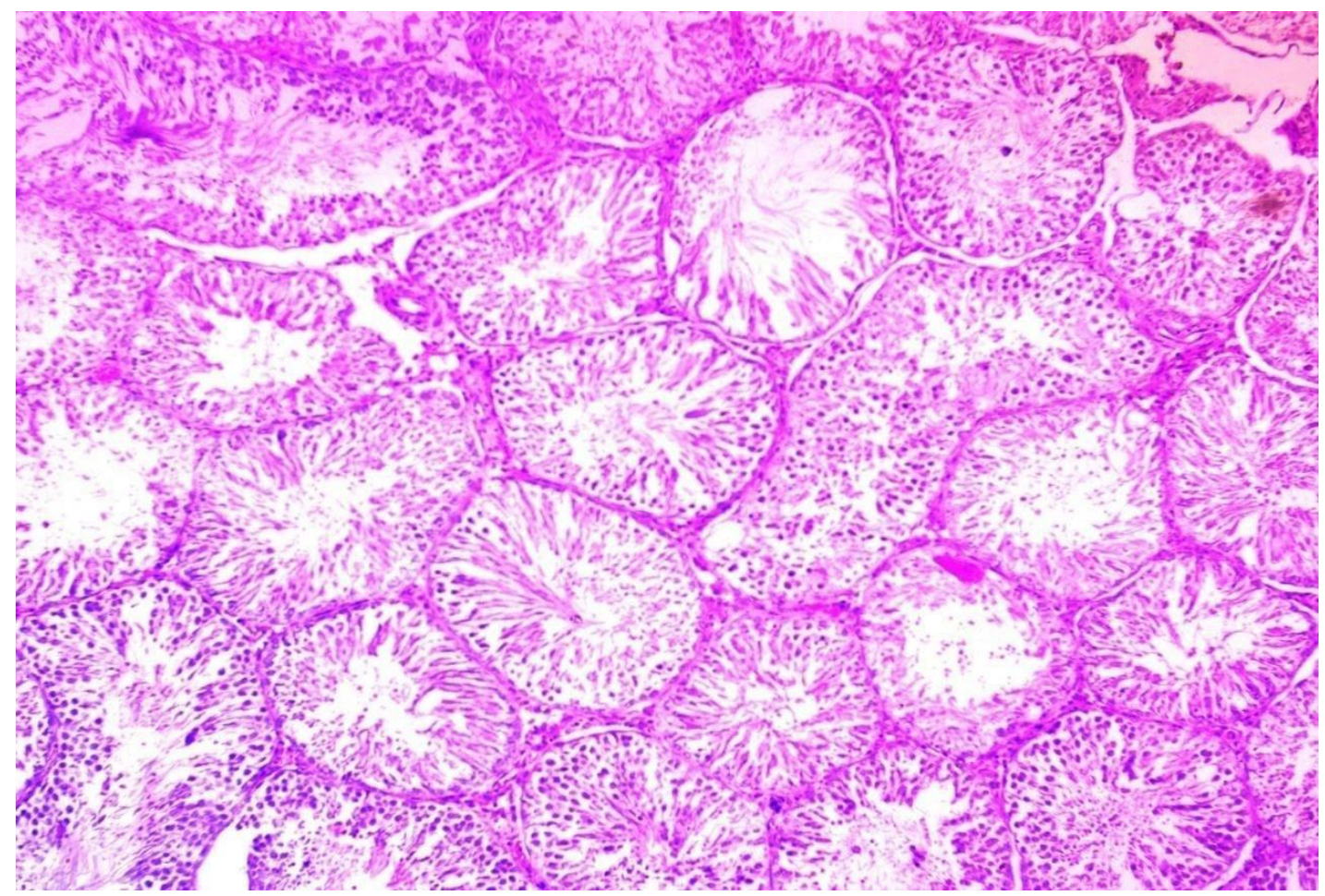


Fig.8 TEM of Group 1 showing spermatogonia (sg) resting on basement membrane (bm), Primary spermatocytes (ps) and round spermatids (rs).UA\&LC2895x

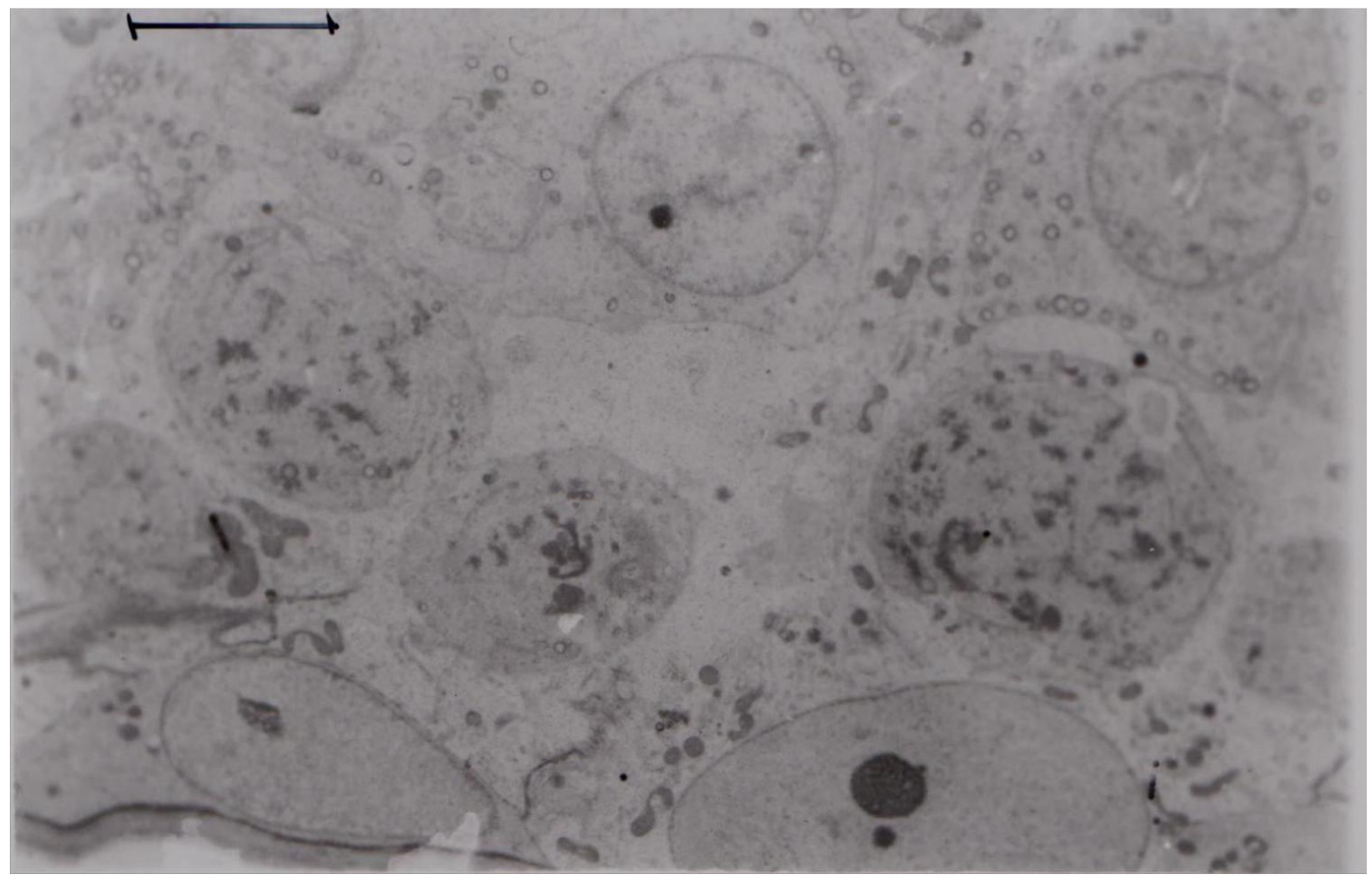

Fig.9 TEM Group 2 showing mild margination of chromatin (arrow) and numerous abnormal Sperms (abs).UA \& LC 2895x

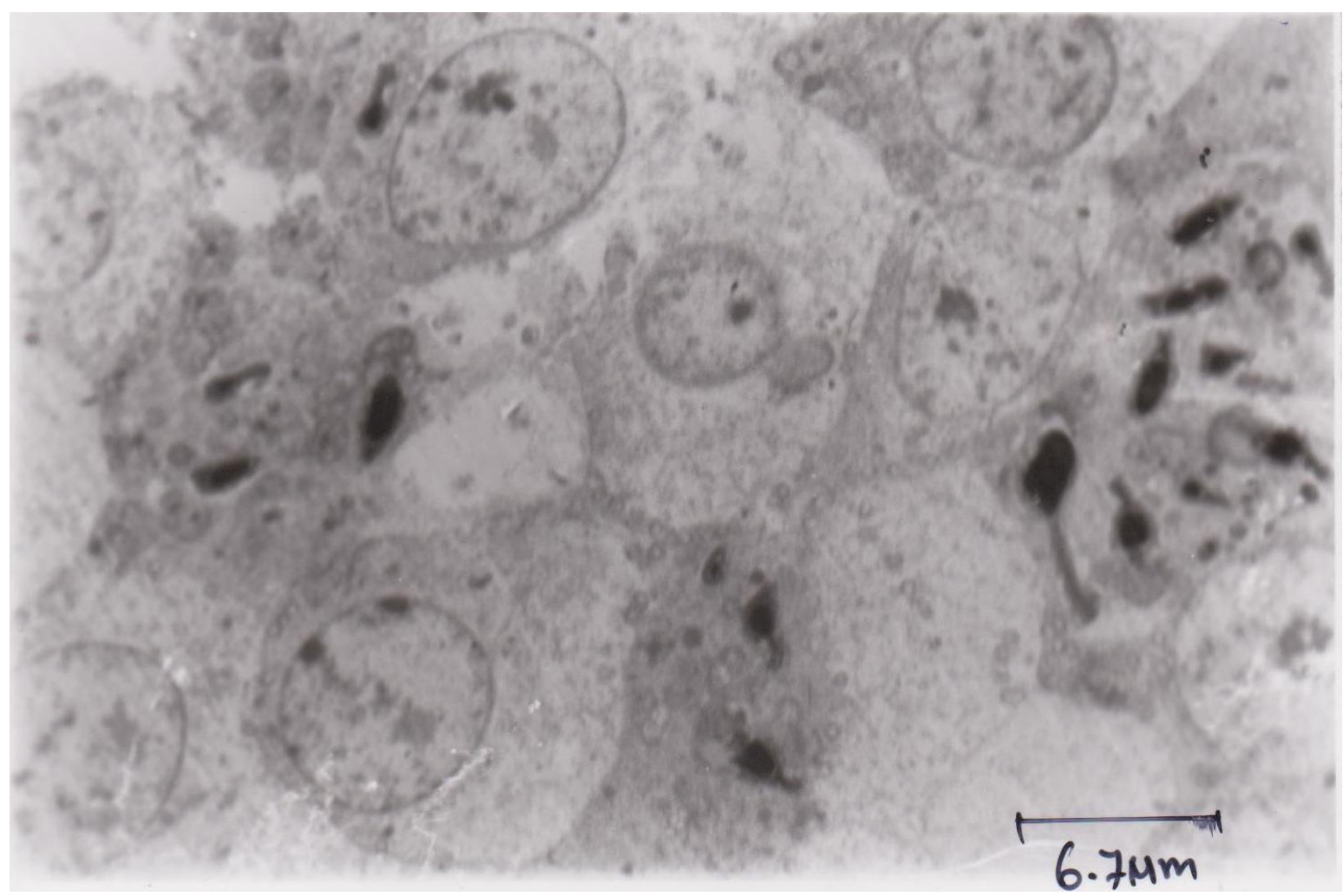


Fig.10 TEM Group 2 on $29^{\text {th }}$ day showing loss of germ cells and severe swelling of Mitochondria (m).UA \& LC 3860x

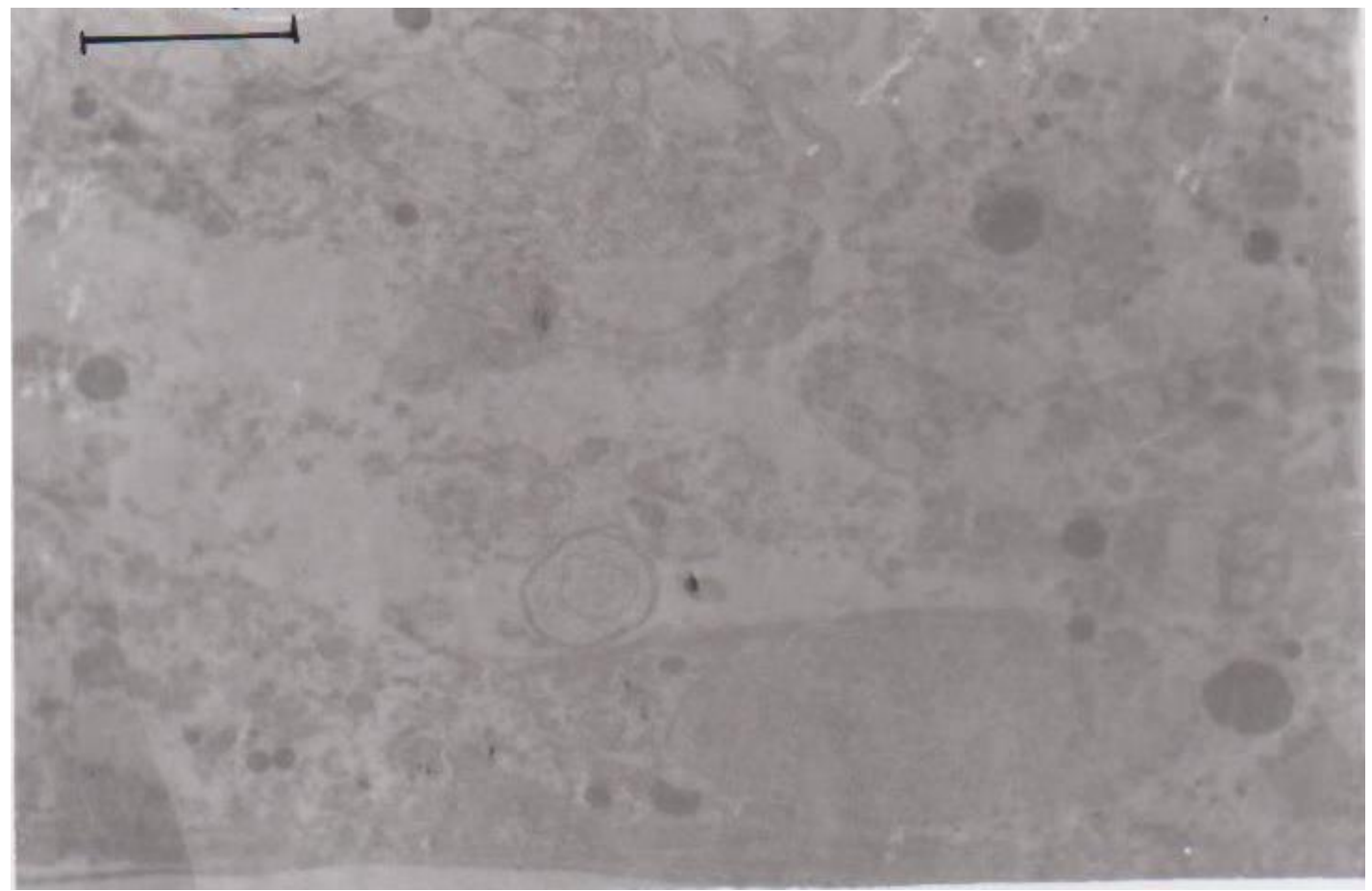

Fig.11 TEM Group 4 showing numerous sperm cells (s) of different size and shapes. UA \& LC 2895x

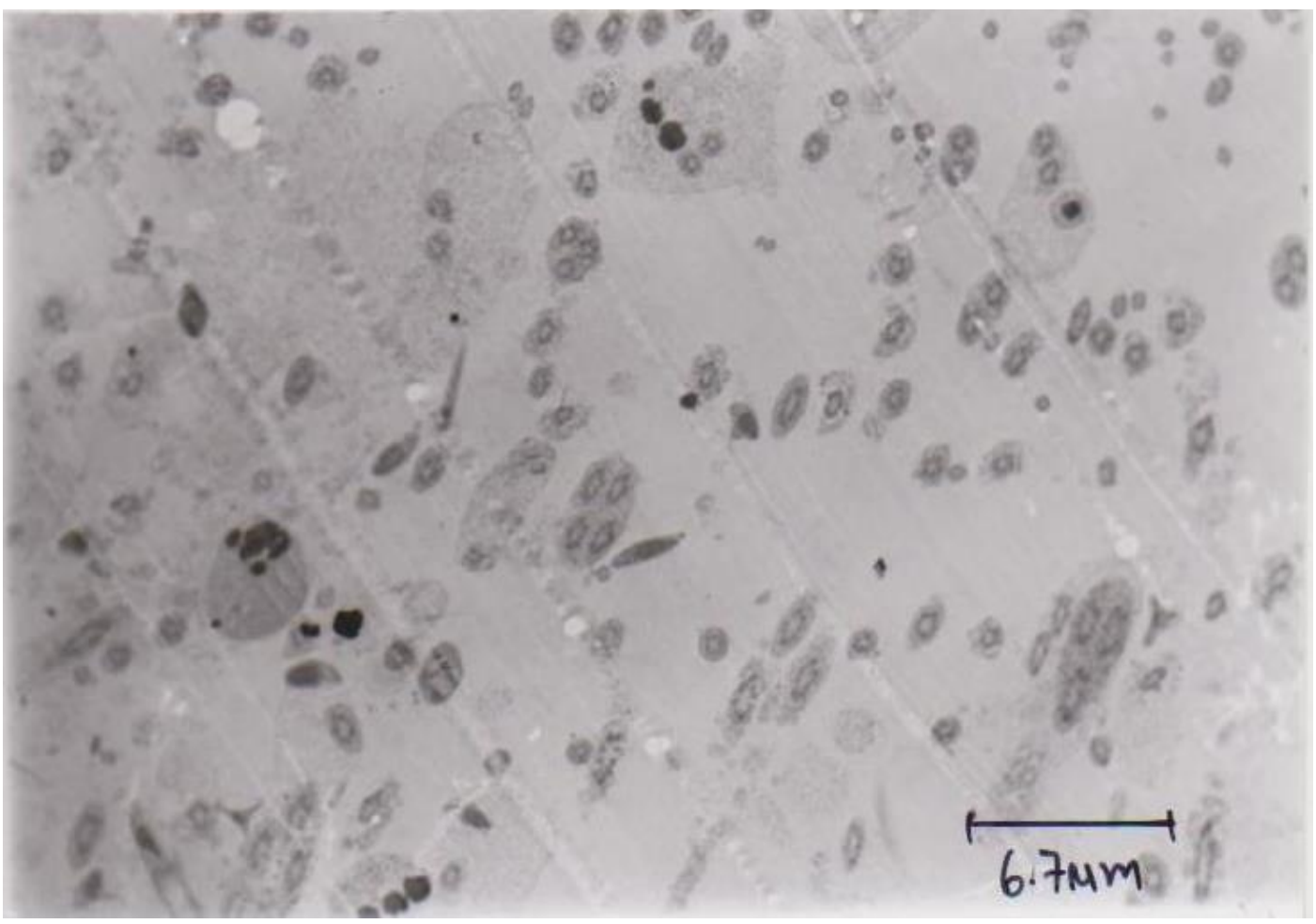


Uniform electron dense lipid bodies were also observed within germ cells. Severe cellular changes like indistinct cellular junctions, absence of spermatocytes and spermatids were observed on 29th day (Fig. 10) in addition to the changes noticed on 15 th day in Group 2. The ultrathin sections of testis in Group 4 on 15th day revealed the presence of spermatogenic cells which appeared to be near normal except with swollen mitochondria. Some spermatogenic cells have showed initiation of acrosomal cap like structure in addition to increase in number of sperm cells (Fig. 11). On 29th day spermatogenesis was evident with presence of spermatogonia, spermatocytes, spermatids and sperm cells. Few germ cells showed mild to moderate degenerative changes like vacuolated cytoplasm, swollen mitochondria and electron dense bodies masked over nucleus.

The present study revealed DOX induced testicular damage as in Group 2 there was significant reduction in absolute and relative testicular weights compared to control. The observations in Group 2 were in accordance with the earlier reports of Kato et al., (2001), Atessahin et al., (2006), Saalu et al., (2009) and Badkoobeh et al., (2013). It is thought that severe parenchymal atrophy in the seminiferous tubules, reduced number of germ cells, atrophy of Leydig cells and lower rate of spermatogenesis after doxorubicin administration in rats causes reduction in testicular weights. The testicular weights of Group 4 were significantly higher than Group 2 indicating protective action of quercetin. Similar findings were reported by Altintas et al., (2015) where quercetin is used as ameliorative agent against docetaxel. Grossly the testicular size was markedly decreased in Group 2 compared with Group 1, which could be due to severe toxic action of DOX on seminiferous tubules. Similar findings were reported by Yeh et al., (2007). Testicular histopathology showed a detectable effect of DOX on spermatogenesis. On day 15 the testicular sections revealed disorganized, disrupted germinal epithelium and shedding of germ cells in to the lumen of tubules. This could be attributed to DOX induced oxidative stress and production of free radicals, this agrees with findings reported by earlier workes (Bashandy and Amin, 2012). In most of the seminiferous tubules vacuolation and severe coagulative necrosis with loss of spermatogenic cells was observed, indicating the degeneration of germcells.

These findings are in accordance with the earlier scientists (kato et al., (2001), Patil et al., (2009), Bashandy and Amin (2012), and Ahmed et al., (2013). The interstitial tissue was widened due to severe edema and vacuoles were noticed, this could be attributed to endothelial dysfunction and oxidative stress in the vascular wall as reported by Venderamani et al., (2010) and Brilhantae et al., (2011). On day 29 the testicular sections showed disrupted spermatogenic cells in many seminiferous tubules. Most of the seminiferous tubules were devoid of germ cells with dilated lumen, indicated that reserve and renewing spermatogonia were harmed (Brilhantaeet al., 2011). In few Seminiferous tubules syncytitia/giant cell formation was noticed. Similar findings were also reported by Brilhantae et al., (2011).

Almost all the seminiferous tubules showed severe atrophy as they are devoid of epithelium. In Group 4 the testicular sections on day 15 and 29 revealed active spermatogenesis with several mitotic figures in spermatogenic cells. In few seminiferous tubules mild degenerative changes and interstitial edema were noticed. Similar findings were reported by Bashandy and Amin (2012). Thus quercetin showed cytoprotection due to its effect on prevention of free radical production in testicular cells, 
so mechanical disruption of epithelium was less. These findings were supported by previous studies demonstrating that active compounds present in quercetin has protective effects against testicular damage caused by different toxic agents such as carbon tetrachloride (Sonmez et al., 2014), docetaxel (Altintas et al., 2015), TCDD (Ciftci et al., 2012) and FNT (Saber et al., 2015).

Ultra structurally Group 2 testes showed prominent sub cellular changes like thinning of basement membrane, distorted spermatogenic cells, peripheral margination of chromatin in spermatocytes, swollen mitochondria, vacuolation of cellular cytoplasm and presence of electron dense lipid bodies during 15th day of experiment. On 29th day severity was more with additional features like indistinct cellular junctions. These findings were in accordance with Prahalathan et al., (2006).

These sub cellular changes could be due to toxic action of doxorubicin on mitochondria, nucleus and cell membranes as a part of oxidative stress induced reaction which were positively correlated with histological parameters. Group 4 ultra-thin sections of testes on 15th and 29th day revealed regeneration and reconstruction of sub cellular structures. There was increase in spermatic cells of different shapes and sizes. Interestingly on 15th day acrosomal cap formation was evident which is indicative of a positive action of ameliorative agent. Besides this the other sub cellular changes like vacuolar changes in cytoplasm were present in most of the sections which are of lesser extent.

The present study indicates reproductive toxicity induced by DOX is related to increased oxidative stress and quercetin a potential antioxidant protects DOX induced testicular toxicity.

\section{References}

Ahmed, F., Urooj, A. and Karim, A. A. 2013. Protective effects of Ficus racemosa stem bark against doxorubucin-induced renal and testicular toxicity. Pharmacognosy magazine 9 (34): 130.

Altintas, R., Ciftci, O., Aydin, M., Akpolat, N., Oguz, F. and Beytur, A. 2015. Quercetin prevents docetaxel- induced testicular damage in rats. Andrologia, 47 (3): 248-256.

Atessahin, A., Karahan, I., Yilmaz, S., Ceribas, A. O. and Bulmus, O. 2006. Lycopene prevents adriamycin-induced testicular toxicity in rats. Fertility and sterility 85: 1216-1222.

Badkoobeh, P., Parivar, K., Kalantar, S. M., Hosseini, S. D. and Salabat, A. 2013. Effect of nano-zinc oxide on doxorubicin-induced oxidative stress and sperm disorders in adult male Wistar rats. Iranian journal of reproductive medicine 11 (5): 355.

Bashandy, M. A. and Amin, S. A. 2012. Curcumin Possible Protective Role in Acute Adriamycin Testicular Toxicity in Adult Male Albino Rats (Histological, Histochemical and Immunohistochemical Study). Journal of American Science 8(9).

Bozzala J. J and Russel L. D. 1998. Electron Microscopy Principles Techniques for Biologists, 2nd Edition: 19-45 and 72144, Jones and Barlett Publishers, Sudbury, Massachusetts.

Brilhante, O., Stumpp, T. and Miraglia, S.M. 2011. Long-term testicular toxicity caused by doxorubicin treatment during pre-pubertal phase. International Journal of Medicine and Medical Sciences 3 (2): 52-60.

Ciftci, O., Aydin, M., Ozdemir, I. and Vardi, N. 2012. Quercetin prevents 2, 3, 7, 8- tetrachlorodibenzo- $\mathrm{p}$ - dioxin- indu 
ced testicular damage in rats. Andrologia 44 (3): 164-173.

Kato, M., Makino, S., Kimura, H., Ota, T., Furuhashi, T. and Nagamura, Y. 2001. Sperm motion analysis in rats treated with adriamycin and its applicability to male reproductive toxicity studies. The Journal of toxicological sciences 26 (1): 51-59.

Luna G. L. H. T. 1968. Manual of Histological and Special Staining Techniques, 2nd Edition: 1-5 and 9-34, the Blakistone Divison McGraw-Hill Book Company, Inc. New York, Toronto London.

Prahalathan, C., Selvakumar, E. and Varalakshmi, P. 2006. Modulatory role of lipoic acid on adriamycin-induced testicular injury. Chemico-biological interactions 160 (2): 108-114.

Saalu, L. C., Enye, L. A. and Osinubi, A. A. 2009. An assessment of the histomorphometric evidences of doxorubicin-induced testicular cytotoxicity in Wistar rats. International Journal of Medicine and Medical Sciences 1 (9): 370-374.

Saber, T. M., Abd El- Aziz, R. M. and Ali, H. A. 2015. Quercetin mitigates fenitrothion- induced testicular toxicity in rats. Andrologia.

Sakanashi, Y., Oyama, K., Matsui, H., Oyama, T. B., Oyama, T. M., Nishimura, Y., Sakai, H. and Oyama, Y. 2008. Possible use of quercetin, an antioxidant, for protection of cells suffering from overload of intracellular $\mathrm{Ca} 2+:$ a model experiment. Life sciences 83 (5): 164-169.

Sonmez, M., Turk, G., Ceribasi, S., Ciftci, M., Yuce, A., Guvenc, M., Ozer Kaya, S., Cay, M. and Aksakal, M. 2014. Quercetin attenuates carbon tetrachloride- induced testicular damage in rats. Andrologia 46 (8): 848858.

Vendramini, V., Sasso-Cerri, E. and Miraglia, S. M. 2010. Amifostine reduces the seminiferous epithelium damage in doxorubicin-treated prepubertal rats without improving the fertility status. Reproductive Biology and Endocrinology 8 (1):1.

Vernet, P., Aitken, R. J. and Drevet, J. R. 2004. Antioxidant strategies in the epididymis. Molecular and cellular endocrinology 216 (1): 31-39.

\section{How to cite this article:}

Divya, S., D. Madhuri, M. Lakshman and Gopal Reddy, A. 2017. Pathological and Ultrastructural Changes in Testis of Rats due to Doxorubicin Toxicity and its Amelioration with Quercetin. Int.J.Curr.Microbiol.App.Sci. 6(7): 2295-2306.

doi: https://doi.org/10.20546/ijcmas.2017.607.330 